\title{
Role of neuronal Ras activity in adult hippocampal neurogenesis and cognition
}

\section{Martina Manns, 1,2 , Oliver Leske ${ }^{3,4}$, Sebastian Gottfried ${ }^{2,3}$, Zoë Bichler $^{3}$, Pauline Lafenêtre ${ }^{4}$, Petra Wahle and $^{2}$ Rolf Heumann ${ }^{2,3 *}$}

\author{
1 Biopsychology, Institute for Cognitive Neuroscience, Faculty for Psychology, Ruhr-University Bochum, Bochum, Germany \\ 2 International Graduate School of Neuroscience, Ruhr-University Bochum, Bochum, Germany \\ ${ }^{3}$ Department of Molecular Neurobiochemistry, Faculty for Chemistry and Biochemistry, Ruhr-University Bochum, Bochum, Germany \\ ${ }^{4}$ Graduate School of Development and Plasticity of the Nervous System, Ruhr-University Bochum, Bochum, Germany \\ ${ }^{5}$ Department of Developmental Neurobiology, Faculty of Biology and Biotechnology, Ruhr-University Bochum, Bochum, Germany
}

\section{Edited by:}

Gerd Kempermann, Center for

Regenerative Therapies, Germany

Reviewed by:

D. Chichung Lie, Helmholtz Zentrum Munchen German Research Center for

Environmental Health, Germany

Benedikt Berninger,

Ludwig-Maximilians-Universität

München, Germany

*Correspondence:

Rolf Heumann, Department of

Molecular Neurobiochemistry, Faculty

for Chemistry and Biochemistry,

Ruhr-University Bochum, NC7/174,

Universitaetsstr. 150, 44780 Bochum,

Germany.

e-mail:rolf.heumann@rub.de
Hippocampal neurogenesis in the adult mammalian brain is modulated by various signals like growth factors, hormones, neuropeptides, and neurotransmitters. All of these factors can (but not necessarily do) converge on the activation of the $G$ protein Ras. We used a transgenic mouse model (synRas mice) expressing constitutively activated G12V-Harvey Ras selectively in differentiated neurons to investigate the possible effects onto neurogenesis. $\mathrm{H}$-Ras activation in neurons attenuates hippocampal precursor cell generation at an early stage of the proliferative cascade before neuronal lineage determination occurs. Therefore it is unlikely that the transgenically activated $\mathrm{H}$-Ras in neurons mediates this effect by a direct, intracellular signaling mechanism. Voluntary exercise restores neurogenesis up to wild type level presumably mediated by brain-derived neurotrophic factor. Reduced neurogenesis is linked to impairments in spatial short-term memory and object recognition, the latter can be rescued by voluntary exercise, as well. These data support the view that new cells significantly increase complexity that can be processed by the hippocampal network when experience requires high demands to associate stimuli over time and/or space.

Keywords: Ras, neurogenesis, hippocampus, memory
In the adult mammalian hippocampus, permanent proliferation of progenitor cells provides a lifelong supply of new neurons that display enhanced plasticity (Snyder et al., 2001; Kempermann et al., 2004b; Schmidt-Hieber et al., 2004; Ge et al., 2007b). Although the young neurons contribute only to a minor fraction of the dentate gyrus (Lagace et al., 2007; Ninkovic et al., 2007), their change in excitability during differentiation (Wang et al., 2005) is likely to make distinct contributions to learning and memory. However, the precise role of the newborn neurons in learning is still under debate (e.g., Kempermann, 2008; Amrein and Lipp, 2009; Deng et al., 2009; Aimone et al., 2010).

A major portion of these young neurons has only a transient existence undergoing apoptosis at early stages of development whereby birth, survival, and differentiation are influenced by countless endogenous and exogenous factors (Ming and Song, 2005; Zhao et al., 2008). Some factors like age, stress, and glucocorticoids downregulate the formation of new nerve cells while others like gonadal hormones, several growth factors, or environmental stimulation have promoting effects (Zhao et al., 2008; Leuner and Gould, 2010; Li and Pleasure, 2010). The impact of factors associated with behavior and cognition suggests that the dynamics of adult neurogenesis is regulated by surrounding network activity (Kempermann, 2008; Li et al., 2009; Deng et al., 2010; Li and Pleasure, 2010). How the activity level of hippocampal networks is conveyed to the progenitor cell population is still unclear. Some evidence exists for activity-dependent restriction on cell lineage development: Excitatory stimuli can act directly on proliferating precursors to favor neuron production via activation of Cav1.2/1.3 (L-type) channels and of NMDA receptors (Deisseroth et al., 2004) mediated by the hippocampal GABAergic system (Tozuka et al., 2005). Moreover, recent research demonstrates a long-lasting epigenetic modulation in expression of neurogenic niche signals via the activity-induced immediate early gene Gadd45b, which is expressed in NeuN positive young dentate granule neurons. Thus, Gadd45b links neuronal circuit activity to region-specific DNA demethylation and controls expression of secreted factors like brain-derived neurotrophic factor (BDNF; Ma et al., 2009). In general, the involvement of neurotrophic factors like BDNF or nerve growth factor (NGF) as well as neurotransmitters like GABA or glutamate have been established, now (Li and Pleasure, 2010; Mu et al., 2010). Additionally, important modulatory roles are ascribed to afferent dopaminergic and cholinergic input (Suh et al., 2009; Itou et al., 2010).

\section{THE synRas MOUSE MODEL}

One critical intracellular switch for conveying neurotrophin- or growth factor signals is the universally expressed GTPase Ras (Heumann, 1994). In order to gain more insight into the role of Ras in neuronal signal transduction and neurotrophin signaling we created a mouse model expressing constitutively activated H-Ras (G12V mutated) selectively in differentiated neurons using a rat synapsin-1 promoter (Heumann et al., 2000; Figure 1). At the cellular level, chronic activation of $\mathrm{H}$-Ras in adult brain neurons leads to enhanced neuronal signaling via the Ras-MAPK pathway but does not activate the PI3-kinase/Akt/PKB pathway. Retrospectively, 
A Extracellular signal

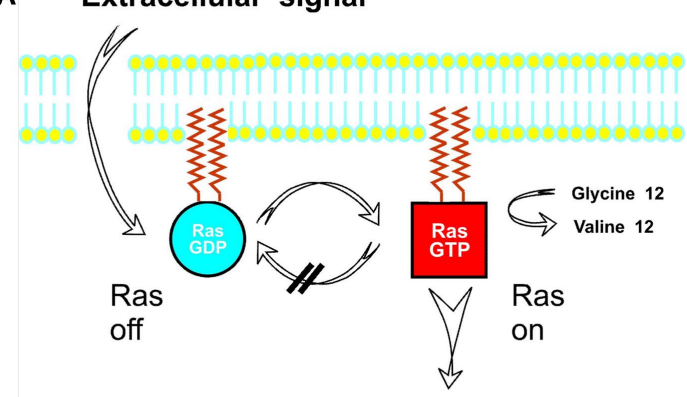

Signal transduction

GTG GGC GCC GGC GGT GTG

Val Gly Ala Gly Gly Val

GTG GGC GCC GTC GGT GTG

Val Gly Ala Val Gly Val

B

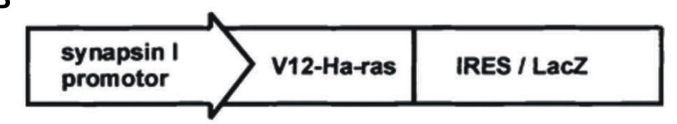

FIGURE 1 | H-Ras is a cytoplasmatic membrane-anchored intracellular protein cycling between the inactive GDP-bound and the signaling active GTP-bound conformation. Due to a glycine to valine point mutation at amino acid 12, Ras GTPase activation by an arginine residue of the GTPase activating protein (GAP) is prevented (Ahmadian et al., 1997), hence leading to a permanent activation of $\mathrm{H}$-Ras (A). Elements of the bicistronic transgene construct consist of the mutated V12-H-Ras gene and the LacZ-reporter gene connected by an internal ribosomal entry site (IRES) so that the H-Ras transgene product and $\beta$-galactosidase are synthesized by the same cell giving rise to separate proteins. Both are expressed under the direction of the neuron specific synapsin I promoter (B)

the most interesting facts about synRas mice in regard to possible interactions with neurogenic pathways are outlined below (a list of major results, especially from extensive neuroanatomical studies can be found in Table 1).

Transgenic activation of $\mathrm{H}$-Ras in post-mitotic neurons protected them from lesion-induced degeneration (Heumann et al., 2000; Makwana et al., 2009). This was shown for facial motor neurons after axonal transection as well as for striatal dopaminergic neurons of the substantia nigra in response to application of the specific dopaminergic neurotoxin $N$-methyl-4-phenyl-1,2,3,6tetrahydropyridine (MPTP). Furthermore, dopamine synthesis is enhanced due to higher activity of tyrosine hydroxylase $(\mathrm{TH}$; the rate-limiting enzyme for dopamine synthesis). Dopamine has been shown to be an important transmitter in hippocampal precursor cell proliferation since administration of the dopamine reuptake inhibitor cocaine leads to diminished proliferation but no changes in survival of adult-formed neurons (Dominguez-Escriba et al., 2006). Moreover, choline acetyl transferase (ChaT; the rate-limiting enzyme for acetylcholine synthesis) activity is enhanced in facial motoneurons (Heumann et al., 2000).

Glutamate synthesis and turnover is also increased in the brain of synRas mice (unpublished observation) and spontaneous AMPA receptor-mediated excitatory post-synaptic currents are more frequent in cortical neurons (Arendt et al., 2004). GABAergic interneu- rons show a different pattern of glutamate decarboxylase mRNA expression compared to wild type siblings though interneurons rarely express the H-Ras transgene (Heumann et al., 2000; Patz et al., 2009). Both, glutamate and GABA are well described neurotransmitters that are involved in the regulation of adult neurogenesis (e.g., Wang et al., 2005; Nacher and McEwan, 2006; Ge et al., 2007a). Interestingly, a switch from an initially excitatory to an inhibitory action of GABA (Ge et al., 2006) and the expression of NMDAR2B receptors (Ge et al., 2007b) characterize the enhanced plasticity of newborn cells in the adult hippocampus.

On the basis of these phenotypic changes in synRas mice the study of adult neurogenesis was started, with surprising results.

\section{NEUROGENESIS IS DIMINISHED IN synRas MICE}

SynRas mice display reduced neurogenesis primarily resulting from a diminished proliferation rate of the progenitor cell population (Lafenêtre et al., 2010; Manns et al., 2010). This has been demonstrated by BrdU-injections that revealed a lower number of BrdUlabeled cells $24 \mathrm{~h}$ after the last of 12 injections. A specific reduction of the newborn neuronal population has been confirmed by double labeling with neuron- and glia-specific markers and by a smaller number of doublecortin-positive cells (Table 1; Lafenêtre et al., 2010; Manns et al., 2010). This effect is exclusive for the adult hippocampus since generation of new cells within the subventricular zone is not affected (Manns et al., 2010). Additionally, doublecortin immunolabeling also demonstrated impaired dendritic differentiation in neuronal precursor cells of synRas mice as indicated by smaller dendritic lengths and a lower number of dendritic segments (Lafenêtre et al., 2010). Attenuated dendritic growth was also detected in Gadd-45b KO mice indicating an essential role of Gadd-45b for activity-induced dendritic growth of newborn neurons in the adult brain (Ma et al., 2009). Thus, the synRas phenotype could be theoretically explained by a downregulation of Gadd-45b. However, we do not favor this hypothesis because the expression level of a well characterized Gadd-45b target gene, BDNF is unchanged in adult synRas cortex or hippocampus (see also Discussion below). Furthermore, the level of Ras in neurons in vivo appears to represent neuronal activation by environmental stimuli (Manns et al., 2005). This would probably lead to a Gadd$45 \mathrm{~b}$ upregulation unless a compensatory inhibition of neuronal network activity is assumed in synRas mice in response to chronic $\mathrm{H}$-Ras activation.

In wild type as well as transgenic animals only a subpopulation of the newborn (BrdU-labeled) cells survives. But the relative survival rate is significantly higher in synRas mice with $55 \%$ compared to $37 \%$ in wild type siblings (Manns et al., 2010). In accordance with the smaller number of newborn cells and their higher survival rate, a significantly lower number of cells can be detected that express caspase-3, an enzyme that acts as an effector of apoptotic cell death (Figure 2A; Table 1). Most caspase-3-immunolabeled cells are located within the subgranular cell layer of the hippocampus suggesting that mainly progenitor cells are targeted for caspase-3 inhibition in synRas mice rather than "old" neurons. This result is in agreement with the observed correlation between the number of proliferating and pyknotic cells in rodent species (Amrein et al., 2004). In contrast to wild type mice, inhibition of progenitor cell proliferation and enhancement of cellular survival 
Table 1 | Summary of the synRas phenotype.

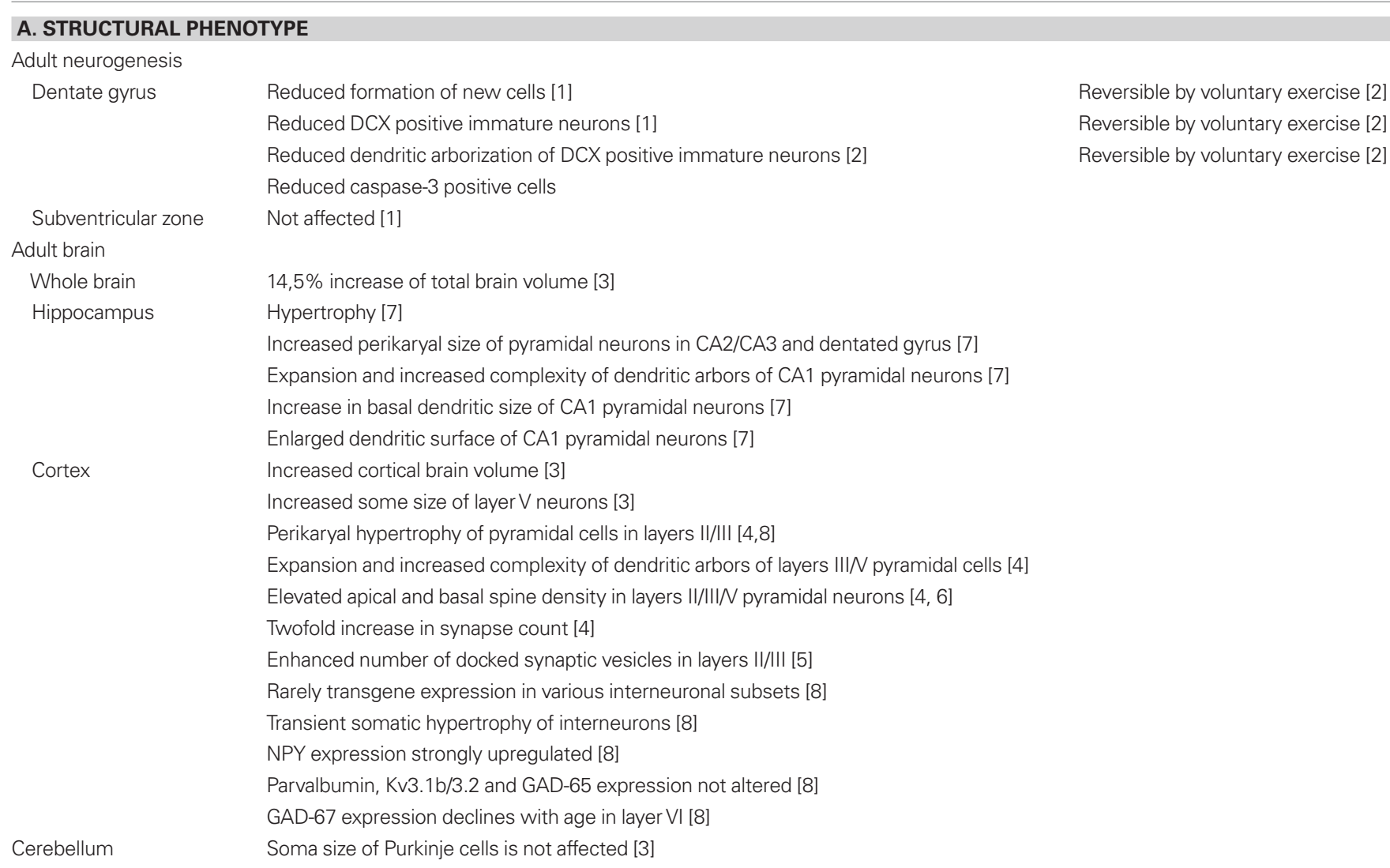

\section{B. BEHAVIORAL PHENOTYPE}

\section{Assessment method \\ Memory \\ Spatial short-term \\ Spatial reference \\ Object recognition

\author{
Radial arm maze \\ Morris water maze \\ Novel object recognition task
}

Anxiety
Elevated plus maze/open field/dark light box
Impaired [1]

Normal [1]

Lack of interest for novel objects, reversible by voluntary exercise [2]

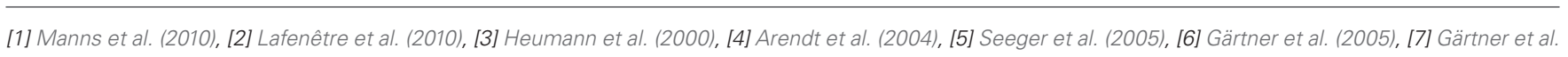
(2004), [8] Patz et al. (2009).

is more pronounced in male compared to female synRas mice. This sex difference suggests a modulation of the H-Ras-mediated effects by gonadal hormones (Manns et al., 2010).

\section{TRANSGENE EXPRESSION IN DIFFERENTIATED NEURONS AFFECTS MITOTIC ACTIVITY OF EARLY PROGENITOR CELLS}

Our BrdU-labeling studies have shown that H-Ras activity has a suppressive effect on the formation of new hippocampal neurons. This difference presumably reveals direct and indirect actions of the transgene protein product. On the one hand, H-Ras-transgene expression shields nerve cells from lesion-induced degeneration (Heumann et al., 2000; Chakrabarty et al., 2007; Makwana et al., 2009). There is previous evidence indicating that intracellular $\mathrm{H}$-Ras activation has a cell-autonomous effect in dissociated single neurons as shown by inhibition of neurotrophin-induced survival after intracellular application of Ras-neutralizing monoclonal antibody or its non-crosslinking $\mathrm{F}_{\mathrm{ab}}$-fragments (Borasio et al., 1989, 1993; Heumann, 1994) Accordingly, enhanced survival of newborn neurons might reflect the neuroprotective action of elevated intracellular H-Ras activity although it cannot be excluded that $\mathrm{H}$-Ras-activated neurons secrete factors other than BDNF, which also contribute to survival effects in synRas animals. However, the synapsin-1 promoter driven H-Ras-transgene expression is confined to differentiated cells (Figure 1B). Thus, decreased early precursor cell proliferation must represent an indirect effect of the activated $\mathrm{H}$-Ras transgene protein. Its expression has been shown to be repressed in nestin-positive neuronal precursors (Chakrabarty et al., 2007). This in turn points to the presence of signals derived 


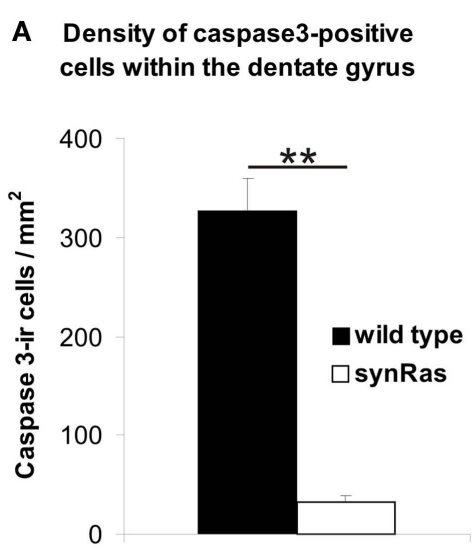

\section{B Density of BrdU-positive cells within the dentate gyrus}

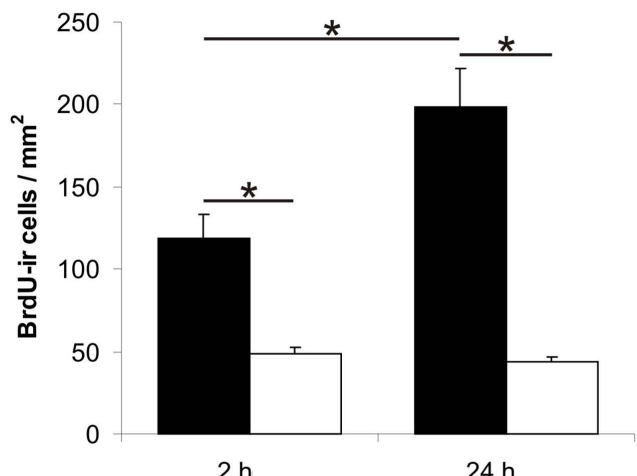

C

\section{Working Hypothesis}

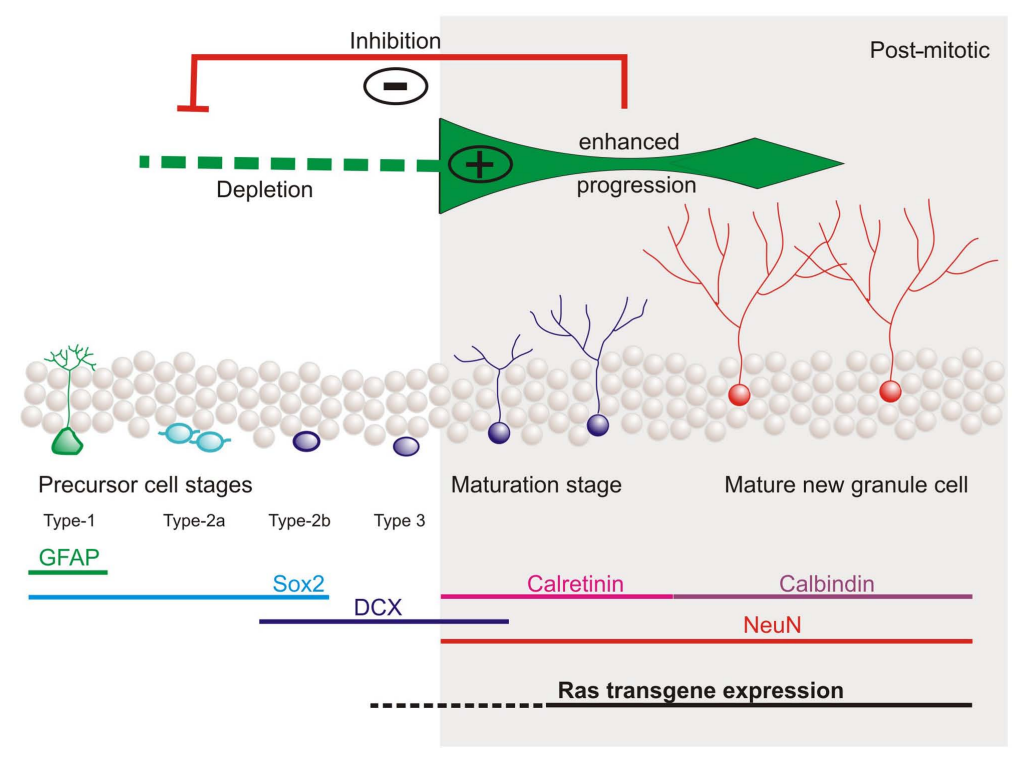

FIGURE 2 | Density of caspase-3 immunoreactive (ir) cells within the dentate gyrus in wild type and synRas mice (A). Density of BrdU immunoreactive cells within the dentate gyrus $2 \mathrm{~h}$ and $24 \mathrm{~h}$ after pulse injection (200 mg/kg BrdU) (B). Bars represent means \pm SEM ( ${ }^{*} p<0.05,{ }^{*} p<0.01$ according to Mann-Whitney U-tests). (C) Working hypothesis for the mechanisms of changes in neurogenesis in synRas mice. For the observed blockade of proliferation a negative feedback inhibition from mature newborn or old neurons to early progenitor cells is conceivable (red) or alternatively a depletion of early progenitors is possible (green, left) by enhancement of progression into mature neurons driven by $\mathrm{H}$-Ras signaling activity in newborn post-mitotic neurons (green, right; figure modified from data by Kempermann et al., 2004a, and Attardo et al., 2010). from the existing hippocampal circuitry as a secondary consequence of H-Ras-transgene expression in differentiated neurons (see "Working Hypothesis" in red in Figure 2C). Neuron-derived feedback regulation of precursor cells has also been suggested by Hastings and Gould (2003) in the olfactory system.

Pulse-injections with BrdU have demonstrated that the synRas activity inhibits neurogenesis already at an early precursor stage of the cell lineage. Two hours after a BrdU-pulse, the density of BrdU-labeled cells is significantly lower in synRas mice compared to wild type siblings (Figure 2B; Manns et al., 2010). At this time point, the major BrdU-labeled cell population represents normally highly proliferative type-2a cells at the transition between the glial and the neuronal lineage (Kronenberg et al., 2003; Kempermann et al., 2004a; Steiner et al., 2006). While the number of BrdU-positive cells increases within $24 \mathrm{~h}$ in wild type animals, their number remains constant in synRas siblings (Manns et al., 2010, Figure 2B). Since BrdU has only a very short bioavailability of $15 \mathrm{~min}$ up to $2 \mathrm{~h}$ (Hayes and Nowakowski, 2000; Mandyam et al., 2007), changes in the number of BrdU-labeled cells result from the mitotic activity of progenitor cells that have incorporated BrdU at the time of injection. Accordingly, unchanged numbers of BrdU-positive cells in synRas mice suggest a low mitotic activity of progenitors in synRas mice. Thus, our data support the hypothesis that 
the transgenic activation of H-Ras in differentiated neurons specifically attenuates mitotic activity of the early type-2a cells (Kronenberg et al., 2003). This may be investigated by determination of precursor cell numbers at particular stages using markers such as GFAP, Sox-2, DCX, and NeuN. The effect on early proliferating cells is specific for the mature hippocampus in synRas mice since the ontogenetic generation of nerve cells is unimpaired (Heumann et al., 2000) and importantly, the number of newborn cells in the subventricular zone is not changed (Manns et al., 2010).

Adult hippocampal progenitors reside in a microenvironment of complex neuronal networks. Within this neurogenic niche, the progression from neural precursor cells to mature neurons is tightly controlled by coordinate cell-intrinsic programs and external signals and numerous molecular pathways have been identified participating in the regulation of adult progenitors (Lledo et al., 2006; Mu et al., 2010).

An important pathway in regulating stem cell self renewal is the wnt/catenin pathway (Gage, 2010). Overexpression of wnt increases hippocampal neurogenesis while blockade of wnt signaling reduces it (Lie et al., 2005). It might be worth investigating if the decreased proliferation of early progenitors in synRas mice is due to a crosstalk between the wnt $/ \beta$-catenin pathway and precursor cell marker Sox-2 (see Gage, 2010). Moreover, in post-mitotic neuronal H-Ras activation increases GSK3 $\beta$ levels in synRas mice (Holzer et al., 2001). Phosphorylation of $\beta$-catenin by GSK3$\beta$ is part of the canonical wnt signaling pathway (Willert and Nusse, 1998) and it remains to be analyzed if deficiencies in aspects of dendritic development in newborn neurons of synRas mice are associated with changes of wnt signaling in post-mitotic neurons (Zhang et al., 2011).

In addition, other factors might play a role: blockade of bone morphogenetic protein (BMB) by application of noggin initially increases neurogenesis but subsequently leads to a decreased stem cell division and depletion of precursors (Mira et al., 2010). Thus, depletion of precursors by chronic stimulation of growth factor signaling pathways in post-mitotic neurons is another hypothesis to explain the synRas phenotype (see Figure 2C, green). Similarly, sonic hedgehog elicites proliferation and pharmacological inhibition of sonic hedgehog signaling reduces it suggesting that regulation of sonic hedgehog is another candidate for the regulatory mechanism in synRas mice (Lai et al., 2003). Furthermore, inflammatory processes have been described to regulate neurogenesis. As neuronal H-Ras supports an anti-apoptotic phenotype the role of pro-inflammatory proteins such as release of interferon gamma might be considered as well in synRas mice (Li et al., 2010).

Sex differences in the suppressive effect on neurogenesis in synRas mice suggest the interaction of $\mathrm{H}$-Ras transgene protein with gonadal hormones (Galea et al., 2006; McEwen, 2010). In female rodents, acute administration of estradiol increases cell proliferation (Tanapat et al., 2005; Barker and Galea, 2008). Since estradiol can directly affect estrogen receptor-expressing hippocampal precursor cells (Isgor and Watson, 2005), suppressive synRas effects might be attenuated by estradiol leading to a higher number of newborn cells in females compared to males. Testosterone conversely up-regulates survival of newborn cells specifically in males (Spritzer and Galea, 2007). Therefore, testosterone might cause the enhanced neuronal survival in male synRas mice by amplifying cell protective effects of the H-Ras-transgene.
Most interestingly, the inhibitory effect of $\mathrm{H}$-Ras transgene expression can be overcome by voluntary exercise that is well known to stimulate adult cell proliferation specifically in the dentate gyrus (Van Praag et al., 1999; Brown et al., 2003). In synRas mice, running increases proliferation of newborn cells in the dentate gyrus up to control level and restores the morphological deficits of doublecortin-positive neurons (Lafenêtre et al., 2010). It has been shown that running stimulates the quiescent Sox-2 positive precursor cell pool (Lugert et al., 2010). Therefore, the results obtained from the running experiments indirectly point to the hypothesis that more Sox-2 cells are in a quiescent state in synRas mice and further supports that proliferation is attenuated at an early stage of the cell lineage in synRas mice. It has been recently observed that the runninginduced effects on proliferation appear to be independent of Notch activity while running-induced survival and enhanced cell cycle exit of type- 3 progenitor cells might be mediated by Notch1 activity (Brandt et al., 2010).H-Ras leads to an activation of Notch signaling and downregulation of tumor suppressor activity in transformed cells (Gustafson et al., 2009). Thus, activation of Notch signaling in neurons remains as another hypothesis to explain the synRas neurogenesis phenotype.

Newborn doublecortin-positive neuronal precursor cells express the BDNF receptor TrkB (Lafenêtre et al., 2010) and its expression is required for an efficient immature-to-mature neuronal transition in the dentate gyrus (Bergami et al., 2008). Accordingly, BDNF infusions increase the number of newborn cells of the adult hippocampus (Scharfman et al., 2005). In turn, voluntary physical activity augments BDNF mRNA and protein levels (Berchtold et al., 2001; Johnson et al., 2003; Adlard et al., 2004; Lafenêtre et al., 2010). Moreover, a nestin-specific knock down of TrkB in early proliferating cells prevented the exercise-induced changes in the hippocampus (Li et al., 2008).

Basic level of BDNF mRNA and protein do not differ between wild type and synRas mice while running increases BDNF in both groups. This suggests that BDNF does not mediate the inhibitory synRas effects onto proliferation of hippocampal precursor cells in non-running animals but supports its role as a mediator of physical exercise (Lafenêtre et al., 2010). BDNF is secreted in an activity-depended manner (Canossa et al., 2001; Lessmann et al., 2003) and stimulates the cell division of early proliferating cells (Chan et al., 2008; Li et al., 2008). In general terms, an environmental stimulus that specifically elevates BDNF may enhance proliferation of progenitor cells and thereby may counteract inhibitory signals or depletion effects derived from differentiated cells (see Figure 2C).

\section{COGNITIVE IMPAIRMENTS OF synRas MICE}

The reduced pool of newly generated nerve cells in synRas mice is related to cognitive impairments in hippocampus-dependent tasks. SynRas mice do not display principal deficits in learning or memory since spatial reference memory as demonstrated in the Morris water maze does not differ from wild type siblings (Manns et al., 2010). This finding is in line with several other models displaying decreased neurogenesis (Leuner et al., 2006; Tashiro et al., 2007). In general, impairments emerge with increasing complexity of behavioral tasks (Wojtowicz et al., 2008; Clelland et al., 2009; Aimone et al., 2010). 
SynRas mice show a profound impairment of spatial short-term memory capacities as demonstrated in the eight arm radial maze. Normally, mice quickly learn to avoid re-entries into already visited arms to minimize energetic costs. Thus, they permanently decrease short-term memory errors. Wild type as well as transgenic siblings acquire the principal rule of the task to visit each arm of the maze only once, but synRas mice are unable to avoid short-term memory errors specifically during the last three arm choices (Manns et al., 2010). Since memory load increases with each arm choice, enhanced numbers of re-entries into already visited arms might represent differences in short-term memory capacities (Manns et al., 2010). A selective deficit in short-term spatial memory was also shown in NF- $\mathrm{\kappa B}$ p50-deficient mice, which display impaired differentiation of newborn cells (Denis-Donini et al., 2008). The observed cognitive deficits in synRas mice support the idea that the size of the pool of newly generated cells has profound effects onto behavioral plasticity. New cells significantly increase complexity that can be processed by the network when experience requires high demands to associate stimuli over time and/or space (Kempermann, 2002, 2008; Winocur et al., 2006; Clelland et al., 2009).

An association of objects over time and space is also necessary for object recognition memory and is also dependent on the integrity of the hippocampus (Squire et al., 2007). Generally, rodents display a spontaneous preference to explore novel objects relative to familiar objects in a specific environmental setting. SynRas mice do not prefer a novel object during critical test sessions of a typical novel object recognition task what is not caused by higher anxiety levels of synRas mice (Lafenêtre et al., 2010). That diminished neurogenesis is related to impaired recognition has also been demonstrated in rats in which adult hippocampal neurogenesis is specifically blocked by a lentiviral approach (Jessberger et al., 2009). These studies provide correlative data for a relation between neurogenesis rate and behavioral performance. A more direct link is indicated here by the fact that running improves novelty recognition in synRas mice compensating memory deficits up to control level parallel to augmented neurogenesis (Lafenêtre et al., 2010). However,

\section{REFERENCES}

Adlard, P. A., Perreau, V. M., EngesserCesar, C., and Cotman, C. W. (2004). The timecourse of induction of brainderived neurotrophic factor mRNA and protein in the rat hippocampus following voluntary exercise. Neurosci. Lett. 363, 43-48.

Ahmadian, M. R., Stege, P., Scheffzek, K., and Wittinghofer, A. (1997). Confirmation of the arginine-finger hypothesis for the GAP-stimulated GTP-hydrolysis reaction of Ras. Nat. Struct. Biol. 4, 686-689.

Aimone, J. B., Deng, W., and Gage, F. H. (2010). Adult neurogenesis: integrating theories and separating functions. Trends Cogn. Sci. 14, 325-337.

Amrein, I., and Lipp, H. P. (2009). Adult hippocampal neurogenesis of mammals: evolution and life history. Biol. Lett. 5, 141-144.
Amrein, I., Slomianka, L., and Lipp, H. P. (2004). Granule cell number, cell death and cell proliferation in the dentate gyrus of wild-living rodents. Eur. J. Neurosci. 20, 3342-3350.

Arendt, T., Gärtner, U., Seeger, G., Barmashenko, G., Palm, K., Mittmann, T., Yan, L., Hümmeke, M., Behrbohm, J., Brückner, M. K., Holzer, M., Wahle, P., and Heumann, R. (2004). Neuronal activation of Ras regulates synaptic connectivity. Eur. J. Neurosci. 19, 2953-2966.

Attardo,A., Fabel, K., Krebs, J., Haubensak, W., Huttner, W. B., and Kempermann, G. (2010). Tis21 expression marks not only populations of neurogenic precursor cells but also new postmitotic neurons in adult hippocampal neurogenesis. Cereb. Cortex 20, 304-314.

Barker, J. M., and Galea, L. A. (2008). Repeated estradiol administration alters different aspects of neurogenesis

since voluntary exercise also enhances the dendritic arborization of the newly generated neurons even in synRas mice (Lafenêtre et al., 2010) it is possible that a better integration of the young neurons into the existing hippocampal network is of relevance for the observed cognitive improvements.

During differentiation, the newly generated cells establish connections with the existing network (Tashiro et al., 2006; Toni et al., 2008) thereby competing with pre-existing dentate granule cells for synaptic space. The outcome of such competition decides about the selective survival or death of new neurons that might have a direct role in a process of learning and memory (Tashiro et al., 2006). Thus, it is conceivable that in synRas mice it is not only the mere number of newly generated cells but also their deficient integration into the network that contributes to the observed cognitive deficits.

\section{SUMMARY}

Our studies suggest that the genetic enhancement of H-RasMAPkinase signaling in adult neurons affects the generation and dendritic differentiation of newborn cells within the adult hippocampus. Neurogenesis is down-regulated at an early stage of the proliferative cascade altering the pool of young highly plastic cells that are critical for hippocampus-dependent learning and memory. Accordingly, synRas mice display impairments in spatial short-term memory and object recognition. Neurogenesis as well as object recognition can be restored by voluntary exercise supporting a link between neurogenesis and hippocampus-dependent cognition. Young neurons might be necessary especially under conditions requiring increasing demands to associate stimuli over time and/or space.

Together, the synRas model shows that the proliferative activity of progenitor cells and their development is subjected to a regulation by signals derived from differentiated nerve cells. However, the actual degree of neurogenesis is controlled by a coordinated interplay of signals derived from different sources converging onto the neurogenic niche.

and cell death in the hippocampus of female, but not male, rats. Neuroscience 152, 888-902.

Berchtold, N. C., Kesslak, J. P., Pike, C. J., Adlard, P. A., and Cotman, C. W. (2001). Estrogen and exercise interact to regulate brain-derived neurotrophic factor mRNA and protein expression in the hippocampus. Eur. J. Neurosci. 14, 1992-2002.

Bergami, M., Rimondini, R., Santi, S., Blum, R., Götz, M., and Canossa, M. (2008) Deletion of TrkB in adult progenitors alters newborn neuron integration into hippocampal circuits and increases anxiety-like behavior. Proc. Natl. Acad. Sci. U.S.A. 105, 15570-15575.

Borasio, G. D., John, J., Wittinghofer, A., Barde, Y. A., Sendtner, M., and Heumann, R. (1989). ras p21 protein promotes survival and fiber outgrowth of cultured embryonic neurons. Neuron 2, 1087-1096.
Borasio, G. D., Markus, A., Wittinghofer, A., Barde, Y. A., and Heumann, R. (1993). Involvement of ras p21 in neurotrophin-induced response of sensory, but not sympathetic neurons. J. Cell Biol. 121, 665-672.

Brandt, M. D., Maass, A., Kempermann, G., and Storch, A. (2010). Physical exercise increases Notch activity, proliferation and cell cycle exit of type-3 progenitor cells in adult hippocampal neurogenesis. Eur. J. Neurosci. 32, 1256-1264.

Brown, J., Cooper-Kuhn, C. M., Kempermann, G., Van Praag, H., Winkler, J., Gage, F. H., and Kuhn, H. G. (2003). Enriched environment and physical activity stimulate hippocampal but not olfactory bulb neurogenesis. Eur. J. Neurosci. 17, 2042-2046.

Canossa, M., Gärtner, A., Campana, G., Inagaki, N., and Thoenen, H. (2001). Regulated secretion of neurotrophins 
by metabotropic glutamate group I (mGluRI) and Trk receptor activation is mediated via phospholipase C signalling pathways. EMBO J. 20, 1640-1650.

Chakrabarty, K., Serchov, T., Mann, S. A., Dietzel, I. D., and Heumann, R. (2007). Enhancement of dopaminergic properties and protection mediated by neuronal activation of Ras in mouse ventral mesencephalic neurones. Eur. J. Neurosci. 25, 1971-1981.

Chan, J. P., Cordeira, J., Calderon, G. A., Iyer, L. K., and Rios, M. (2008). Depletion of central BDNF in mice impedes terminal differentiation of new granule neurons in the adult hippocampus. Mol. Cell. Neurosci. 39, 372-383.

Clelland, C. D., Choi, M., Romberg, C., Clemenson, G. D. Jr., Fragniere, A., Tyers, P., Jessberger, S., Saksida, L. M., Barker, R. A., Gage, F. H., and Bussey, T. J. (2009). A functional role for adult hippocampal neurogenesis in spatial pattern separation. Science $325,210-213$.

Deisseroth, K., Singla, S., Toda, H., Monje, M., Palmer, T. D., and Malenka, R. C. (2004). Excitation-neurogenesis coupling in adult neural stem/progenitor cells. Neuron 42, 535-552.

Deng, W., Aimone, J. B., and Gage, F. H. (2010). New neurons and new memories: how does adult hippocampal neurogenesis affect learning and memory? Nat. Rev. Neurosci. 11, 339-350.

Deng, W., Saxe, M. D., Gallina, I. S., and Gage, F.H. (2009). Adult-born hippocampal dentate granule cells undergoing maturation modulate learning and memory in the brain. J. Neurosci. 29, 13532-13542.

Denis-Donini, S., Dellarole, A., Crociara, P., Francese, M. T., Bortolotto, V., Quadrato, G., Canonico, P. L., Orsetti, M., Ghi, P., Memo, M., Bonini, S. A., Ferrari-Toninelli, G., and Grilli, M. (2008). Impaired adult neurogenesis associated with short-term memory defects in NF-kappaB p50-deficient mice. J. Neurosci. 28, 3911-3919.

Dominguez-Escriba, L., HernendezRabaza, V., Soriano-Navarro, M., Barcia, J. A., Romero, F. J., GarciaVerdugo, J.M., and Canales, J.J. (2006). Chronic cocaine exposure impairs progenitor proliferation but spares survival and maturation of neural precursors in adult rat dentate gyrus. Eur. J. Neurosci. 24, 586-594.

Gage, F. H. (2010). Molecular and cellular mechanisms contributing to the regulation, proliferation and differentiation of neural stem cells in the adult dentate gyrus. Keio J. Med. 59, 79-83.

Galea, L. A., Spritzer, M. D., Barker, J. M., and Pawluski, J. L. (2006). Gonadal hormone modulation of hippocampal neurogenesis in the adult. Hippocampus 16, 225-232.

Gärtner, U., Alpár, A., Behrbohm, J., Heumann, R., and Arendt, T. (2005). Enhanced Ras activity promotes spine formation in synRas mice neocortex. Neuroreport 16, 149-152.

Gärtner, U., Alpár, A., Seeger, G., Heumann, R., and Arendt, T. (2004). Enhanced Ras activity in pyramidal neurons induces cellular hypertrophy and changes in afferent and intrinsic connectivity in synRas mice. Int. J. Dev. Neurosci. 22, 165-173.

Ge, S., Goh, E. L., Sailor, K. A., Kitabatake, Y., Ming, G. L., and Song, H. (2006). GABA regulates synaptic integration of newly generated neurons in the adult brain. Nature 439, 589-593.

Ge, S., Pradhan, D. A., Ming, G. L., and Song, H. (2007a). GABA sets the tempo for activity-dependent adult neurogenesis. Trends Neurosci. 30, $1-8$.

Ge, S., Yang, C. H., Hsu, K. S., Ming, G. L., and Song, H. (2007b). A critical period for enhanced synaptic plasticity in newly generated neurons of the adult brain. Neuron 54, 559-566.

Gustafson, T. L., Wellberg, E., Laffin, B., Schilling, L., Metz, R. P., Zahnow, C. A., and Porter, W. W. (2009). Ha-Ras transformation of MCF10A cells leads to repression of Singleminded-2s through NOTCH and C/EBPbeta. Oncogene 28, 1561-1568.

Hastings, N. B., and Gould, E. (2003). Neurons inhibit neurogenesis. Nat. Med. 9, 264-266.

Hayes, N. L., and Nowakowski, R. S. (2000). Exploiting the dynamics of S-phase tracers in developing brain: interkinetic nuclear migration for cells entering versus leaving the S-phase. Dev. Neurosci. 22, 44-55.

Heumann, R. (1994). Neurotrophin signalling. Curr. Opin. Neurobiol. 4, 668-679.

Heumann, R., Goemans, C., Bartsch, D., Lingenhöhl, K., Waldmeier, P. C., Hengerer, B., Allegrini, P. R., Schellander, K., Wagner, E. F., Arendt, T., Kamdem, R. H., Obst-Pernberg, K., Narz, F., Wahle, P., and Berns, H. (2000). Transgenic activation of Ras in neurons promotes hypertrophy and protects from lesion-induced degeneration. J. Cell Biol. 151, 1537-1548.

Holzer, M., Gartner, U., Klinz, F., Narz, F., Heumann, R., and Arendt, T. (2001). Activation of mitogen-activated protein kinase cascade and phosphorylation of cytoskeletal proteins after neurone-specific activation of p21ras. I. Mitogen-activated protein kinase cascade. Neuroscience 105, 1031-1040.

Isgor, C., and Watson, S. J. (2005). Estrogen receptor alpha and beta mRNA expres- sions by proliferating and differentiating cells in the adult rat dentate gyrus and subventricular zone. Neuroscience $134,847-856$.

Itou, Y., Nochi, R., Kuribayashi, H., Saito, Y., and Hisatsune, T. (2010). Cholinergic activation of hippocampal neural stem cells in aged dentate gyrus. Hippocampus. [Epub ahead of print].

Jessberger, S., Clark, R. E., Broadbent, N. J., Clemenson, G. D. Jr., Consiglio, A., Lie, D. C., Squire, L. R., and Gage, F. H. (2009). Dentate gyrus-specific knockdown of adult neurogenesis impairs spatial and object recognition memory in adult rats. Learn. Mem. 16 147-154.

Johnson, R. A., Rhodes, J. S., Jeffrey, S. L., Garland, T. Jr., and Mitchell, G. S. (2003). Hippocampal brain-derived neurotrophic factor but not neurotrophin-3 increases more in mice selected for increased voluntary wheel running. Neuroscience 121, 1-7.

Kempermann, G. (2002). Why new neurons? Possible functions for adult hippocampal neurogenesis. J. Neurosci. 22, 635-638.

Kempermann, G. (2008). The neurogenic reserve hypothesis: what is adult hippocampal neurogenesis good for? Trends Neurosci. 31, 163-169.

Kempermann, G., Jessberger, S., Steiner B., and Kronenberg, G. (2004a). Milestones of neuronal development in the adult hippocampus. Trends Neurosci. 27, 447-452.

Kempermann, G., Wiskott, L., and Gage, F. H. (2004b). Functional significance of adult neurogenesis. Curr. Opin. Neurobiol. 14, 186-191.

Kronenberg, G., Reuter, K., Steiner, B., Brandt, M. D., Jessberger, S., Yamaguchi, M., and Kempermann, G. (2003). Subpopulations of proliferating cells of the adult hippocampus respond differently to physiologic neurogenic stimuli. J. Comp. Neurol. $467,455-463$.

Lafenêtre, P., Leske, O., Ma-Högemeie, Z., Haghikia, A., Bichler, Z., Wahle, P., and Heumann, R. (2010). Exercise can rescue recognition memory impairment in a model with reduced adult hippocampal neurogenesis. Front. Behav. Neurosci. 3:34. doi: 10.3389/ neuro.08.034.2009

Lagace, D. C., Whitman, M. C., Noonan, M. A., Ables, J. L., DeCarolis, N. A., Arguello, A. A., Donovan, M. H., Fischer, S. J., Farnbauch, L. A., Beech, R. D., DiLeone, R. J., Greer C. A., Mandyam, C. D., and Eisch, A. J. (2007). Dynamic contribution of nestin-expressing stem cells to adult neurogenesis. J. Neurosci. 27 , 12623-12629.

Lai, K., Kaspar, B. K., Gage, F. H., and Schaffer, D.V. (2003). Sonic hedgehog regulates adult neural progenitor proliferation in vitro and in vivo. Nat Neurosci. 6, 21-27.

Lessmann, V., Gottmann, K., and Malcangio, M. (2003). Neurotrophin secretion: current facts and future prospects. Prog. Neurobiol. 69, 341-374.

Leuner, B., and Gould,E. (2010).Structural plasticity and hippocampal function. Annu. Rev. Psychol. 61, 111-140.

Leuner, B., Waddell, J., Gould, E., and Shors, T. J. (2006). Temporal discontiguity is neither necessary nor sufficient for learning-induced effects on adult neurogenesis. J. Neurosci. 27, 13437-13442.

Li, G., and Pleasure, S. J. (2010). Ongoing interplay between the neural network and neurogenesis in the adult hippocampus. Curr. Opin. Neurobiol. 20, 126-133.

Li, L., Walker, T. L., Zhang, Y., Mackay, E. W., and Bartlett, P. F. (2010). Endogenous interferon gamma directly regulates neural precursors in the non-inflammatory brain. $J$. Neurosci. 30, 9038-9050.

Li, Y., Luikart, B. W., Birnbaum, S., Chen, J., Kwon, C. H., Kernie, S. G., BasselDuby, R., and Parada, L. F. (2008). TrkB regulates hippocampal neurogenesis and governs sensitivity to antidepressive treatment. Neuron 59, 399-412.

Li, Y., Mu, Y., and Gage, F. H. (2009). Development of neural circuits in the adult hippocampus. Curr. Top. Dev. Biol. 87, 149-174.

Lie, D. C., Colamarino, S. A., Song, H. J., Désiré, L., Mira, H., Consiglio, A., Lein, E. S., Jessberger, S., Lansford, H., Dearie, A. R., and Gage, F. H. (2005). Wnt signalling regulates adult hippocampal neurogenesis. Nature 437, 1370-1375.

Lledo, P. M., Alonso, M., and Grubb, M. S. (2006). Adult neurogenesis and functional plasticity in neuronal circuits. Nat. Rev. Neurosci. 7, 179-193.

Lugert, S., Basak, O., Knuckles, P., Haussler, U., Fabel, K., Götz, M., Haas, C. A., Kempermann, G., Taylor, V., and Giachino, C. (2010). Quiescent and active hippocampal neural stem cells with distinct morphologies respond selectively to physiological and pathological stimuli and aging. Cell Stem Cell 6, 445-456.

Ma, D. K., Jang, M. H., Guo, J. U., Kitabatake, Y., Chang, M. L., PowAnkongkul, N., Flavell, R. A., Lu, B., Ming, G. L., and Song, H. (2009). Neuronal activity-induced Gadd45b promotes epigenetic DNA demethylation and adult neurogenesis. Science 323, 1074-1077.

Makwana, M., Serchov, T., Hristova, M., Bohatschek, M., Gschwendtner, A. Kalla, R., Liu, Z., Heumann, R., and Raivich, G. (2009). Regulation and 
function of neuronal GTP-Ras in facial motor nerve regeneration. $J$. Neurochem. 108, 1453-1463.

Mandyam, C. D., Harburg, G. C., and Eisch, A. J. (2007). Determination of key aspects of precursor cell proliferation, cell cycle length and kinetics in the adult mouse subgranular zone. Neuroscience 146, 108-122.

Manns, M., Bichler, Z., Leske, O., and Heumann, R. (2010). Neuronal Ras activation inhibits adult hippocampal progenitor cell division and impairs spatial short-term memory. Genes Brain Behav. 9, 525-536.

Manns, M., Güntürkün, O., Heumann, R., and Blöchl, A. (2005). Photic inhibition of TrkB/Ras activity in the pigeon's tectum during development: impact on brain asymmetry formation. Eur. J. Neurosci. 22, 2180-2186.

McEwen, B. S. (2010). Stress, sex, and neural adaptation to a changing environment: mechanisms of neuronal remodeling. Ann. N. Y. Acad. Sci. 1204(Suppl.), E38-E59.

Ming, G. L., and Song, H. (2005). Adult neurogenesis in the mammalian central nervous system. Annu. Rev. Neurosci. 28, 223-250.

Mira, H., Andreu, Z., Suh, H., Lie, D. C., Jessberger, S., Consiglio, A., San Emeterio, J., Hortigüela, R., MarquésTorrejón, M.A., Nakashima, K., Colak, D., Götz, M., Fariñas, I., and Gage, F. H. (2010). Signaling through BMPR-IA regulates quiescence and long-term activity of neural stem cells in the adult hippocampus. Cell Stem Cell 7, 78-89.

Mu, Y., Lee, S. W., and Gage, F. H. (2010). Signaling in adult neurogenesis. Curr. Opin. Neurobiol. 20, 416-423.

Nacher, J., and McEwan, B. S. (2006). The role of N-methyl-D-aspartate receptors in neurogenesis. Hippocampus $16,267-270$.
Ninkovic, J., Mori, T., and Götz, M. (2007). Distinct modes of neuron addition in adult mouse neurogenesis. J. Neurosci. 27, 10906-10911.

Patz, S., Colovic, C., Wawro, S., Lafenetre, P., Leske, O., Heumann, R. Schönfelder, S., Tomaschewski, J., Räk, A., and Wahle, P. (2009). Interneuronal growth and expression of interneuronal markers in visual cortex of mice with transgenic activation of Ras. Exp. Brain Res. 199, 265-278.

Scharfman, H., Goodman, J., Macleod, A., Phani, S., Antonelli, C., and Croll, S. (2005). Increased neurogenesis and the ectopic granule cells after intrahippocampal BDNF infusion in adult rats. Exp. Neurol. 192, 348-356.

Schmidt-Hieber, C., Jonas, P., and Bischofberger, J. (2004). Enhanced synaptic plasticity in newly generated granule cells of the adult hippocampus. Nature 429, 184-187.

Seeger, G., Gärtner, U., and Arendt, T. (2005). Transgenic activation of Ras in neurons increases synapse formation in mouse neocortex. J. Neural Transm. 112, 751-761.

Snyder, J. S., Kee, N., and Wojtowicz, J. M. (2001). Effects of adult neurogenesis on synaptic plasticity in the rat dentate gyrus. J. Neurophysiol. 85, 2423-2431.

Spritzer, M. D., and Galea, L. A. (2007). Testosterone and dihydrotestosterone, but not estradiol, enhance survival of newhippocampalneurons in adult male rats. Dev. Neurobiol. 67, 1321-1333.

Squire, L. R., Wixted, J. T., and Clark, R.E. (2007). Recognition memory and the medial temporal lobe: a new perspective. Nat. Rev. Neurosci. 8, 872-883.

Steiner, B., Klempin, F., Wang, L., Kott, M., Kettenmann, H., and Kempermann, G. (2006). Type-2 cells as link between glial and neuronal lineage in adult hippocampal neurogenesis. Glia 54, 805-814.
Suh, H., Deng, W., and Gage, F. H. (2009). Signaling in adult neurogenesis. Annu. Rev. Cell Dev. Biol. 25, 253-275.

Tanapat, P., Hastings, N. B., and Gould, E. (2005). Ovarian steroids influence cell proliferation in the dentate gyrus of the adult female rat in a dose- and time-dependent manner. J. Comp. Neurol. 481, 252-265.

Tashiro, A., Makino, H., and Gage, F. H. (2007). Experience-specific functional modification of the dentate gyrus through adult neurogenesis: a critical period during an immature stage. $J$. Neurosci. 27, 3252-3259.

Tashiro, A., Sandler, V. M., Toni, N., Zhao, C., and Gage, F. H. (2006). NMDA-receptor-mediated, cellspecific integration of new neurons in adult dentate gyrus. Nature 442, 929-933.

Toni, N., Laplagne, D. A., Zhao, C., Lombardi, G., Ribak, C. E., Gage, F.H., and Schinder, A. F. (2008). Neurons born in the adult dentate gyrus form functional synapses with target cells. Nat. Neurosci. 11, 901-907.

Tozuka, Y., Fukuda, S., Namba, T., Seki, T., and Hisatsune, T. (2005). GABAergic excitation promotes neuronal differentiation in adult hippocampal progenitor cells. Neuron 47, 803-815.

Van Praag, H., Kempermann, G., and Gage, F. H. (1999). Running increases cell proliferation and neurogenesis in the adult mouse dentate gyrus. Nat. Neurosci. 2, 266-270.

Wang, L. P., Kempermann, G., and Kettenmann, H. (2005). A subpopulation of precursor cells in the mouse dentate gyrus receives synaptic GABAergic input. Mol. Cell. Neurosci. 29, 181-189.

Willert, K., and Nusse, R. (1998). Betacatenin: a key mediator of Wnt signaling. Curr. Opin. Genet. Dev. 8, 95-102.
Winocur, G., Wojtowicz, J. M., Sekeres, M., Snyder, J. S., and Wang, S. (2006). Inhibition of neurogenesis interferes with hippocampus-dependent memory function. Hippocampus 16, 296-304.

Wojtowicz, J. M., Askew, M. L., and Winocur, G. (2008). The effect of running and inhibiting adult neurogenesis on learning and memory in rats. Eur. J. Neurosci. 27, 1494-1502.

Zhang, L., Yang, X., Yang, S., and Zhang, J. (2011). The wnt/b-catenin signaling pathway in adult neurogenesis. Eur. J. Neurosci. 33, 1-8.

Zhao, C., Deng, W., and Gage, F.H. (2008). Mechanisms and functional implications of adult neurogenesis. Cell 132, 645-660.

Conflict of Interest Statement: The authors declare that the research was conducted in the absence of any commercial or financial relationships that could be construed as a potential conflict of interest.

Received: 19 November 2010; paper pending published: 14 December 2010; accepted: 01 February 2011; published online: 14 February 2011.

Citation: Manns M, Leske O, Gottfried $S$, Bichler Z, Lafenetre P, Wahle P and Heumann R (2011) Role of neuronal Ras activity in adult hippocampal neurogenesis and cognition. Front. Neurosci. 5:18. doi: 10.3389/fnins.2011.00018

This article was submitted to Frontiers in Neurogenesis, a specialty of Frontiers in Neuroscience.

Copyright (C) 2011 Manns, Leske, Gottfried, Bichler, Lafenetre, Wahle and Heumann. This is an open-access article subject to an exclusive license agreement between the authors and Frontiers Media SA, which permits unrestricted use, distribution, and reproduction in any medium, provided the original authors and source are credited. 